\title{
Flow Field and Reynolds Stress Distribution in Low Turbulence Natural Convection in a Triangular Cavity
}

\author{
S.O. Talabi ${ }^{1}$, V.O.S. Olunloyo ${ }^{1}$, O.M. Kamiyo ${ }^{1}$, M.W. Collins ${ }^{2}$, \\ and T.G. Karayiannis ${ }^{2}$ \\ ${ }^{1}$ Faculty of Engineering, University of Lagos, Lagos, Nigeria, sotalabi@ hotmail.com, \\ vosolunloyo@hotmail.com, ola_kamiyo@hotmail.com \\ ${ }^{2}$ School of Engineering and Design, Brunel University, Middlesex, U.K., \\ collinmw@hotmail.com, tassos.karayiannis@brunel.ac.uk
}

\begin{abstract}
Triangular enclosures are typical configurations found in attic spaces of residential as well as industrial pitched-roof buildings. Previous studies on airflow within such spaces have focused on the laminar range. A numerical study has been carried out for time-dependent, two-dimensional low turbulence natural convection of air contained in the attic of a pitched roof of triangular crosssection. Two sets of boundary conditions have been considered: enclosure heated from the inclined walls and from the horizontal base wall, for aspect ratios (AR) of $0.33 \leq \mathrm{AR} \leq 1.73$ for Rayleigh number $(\mathrm{Ra}), 10^{9} \leq \mathrm{Ra} \leq 10^{11}$. In this paper, the flow field and Reynolds stress distribution are presented for the isothermal and isoflux cases.
\end{abstract}

\section{Introduction}

Natural convection in enclosures with differentially heated sidewalls is of importance in many engineering applications. These include energy transfer in rooms and buildings, nuclear reactor cooling, solar collectors and electronic equipment cooling. In many types of buildings, both single and multi-storey, including schools, offices, churches, factories and residential buildings, the attic space is often given paramount consideration because its thermal characteristics have great influence on the conditions of the space directly below it. A significant amount of the cooling load in residential and industrial buildings is the result of heat transfer across the ceiling from the attic. For example, in the tropics, conventional types of roof construction suffer from excessive mid-day overheating due to high incident solar radiation. Solar absorption, in equilibrium with the radiative emissivity, will cause the roofing sheets in the midday sun to become very hot resulting in temperatures often exceeding $80^{\circ} \mathrm{C}$ in some cases. The larger the roof area, the greater the difficulty in controlling the overheating of the building interior. Also, in some rural areas in the tropics, agricultural products are sometimes kept in the rooftops of residences either for drying or for storage. It is, therefore, pertinent to have a thorough knowledge of the airflow pattern within the attic space in realistic conditions.

Natural convection in an enclosure is as varied as the enclosure geometry, its orientation and thermal boundary conditions. According to Bejan [1], the thermal conditions can be divided into two separate classes: (i) enclosures heated from the sides, and (ii) enclosures heated from below. A triangular enclosure heated from below or from the sides has an important application for heat transfer through a triangular-shaped attic space where different temperatures along the sloped walls and horizontal base wall represent winter and summer conditions respectively. Natural convection in triangular enclosures has received considerable attention over the years. The first numerical study was carried out by Gershuni et al. [2] in 
1974 while the first experiment was conducted by Thirst and Probert [3] in 1978. Akinsete and Coleman [4], Ghassemi and Roux [5], Hasani and Chung [6], and Asan and Namli [7] were among the numerical investigators of cavities heated from the inclined walls while Poulikakos and Bejan [8], Salmun [9] and Holtzman et al.[10] studied cavity heated from the base wall. Flack [11] was among the few that studied both cases. The seven possible nontrivial combinations of isothermal and adiabatic boundary conditions were investigated by del Campo et al. [12].

Unlike many authors that assumed symmetry for the isosceles triangular cavity, Karyakin et al. [13] used the entire triangular region for cavity heated from the inclined walls. The asymmetrical flow pattern obtained confirmed their suspicion of the validity of results obtained with symmetry assumption. Holtzman et al. [10] studied the effects of the symmetry assumption made by some of the previous authors. They found that a pitchfork bifurcation occurred at a critical Grashof (Gr) number above which the flow pattern became increasingly asymmetric and the number of counter-rotating cells increased.

However, the magnitude of the Rayleigh number used for their flows was a limiting factor in the studies described above. In the work by Akinsete and Coleman [4] and Asan and Namli [7], the maximum value for Ra used was $4.5 \times 10^{4}$. Poulikakos and Bejan [8] and Hasani and Chung [6] stated that this range was too small. The latter claimed that the values of Ra should be as high as $10^{6}$. Nevertheless, the results still show laminar flow situations. For an actual size attic, however, a Rayleigh number as high as $10^{10}$ or $10^{11}$ is expected. Only Haese and Teubner [14] investigated this range for cavity heated from the base but failed to apply turbulence modelling. Hence, turbulent quantities could not be reported. Also, the significant effects of symmetry assumption were ignored. In the present study, numerical study of turbulent natural convection of air contained in an actual-size horizontal isosceles triangular enclosure is investigated using turbulence models. A high Ra range between $10^{9}$ and $10^{11}$ was considered to realistically simulate an actual size attic.

\section{Computational Details}

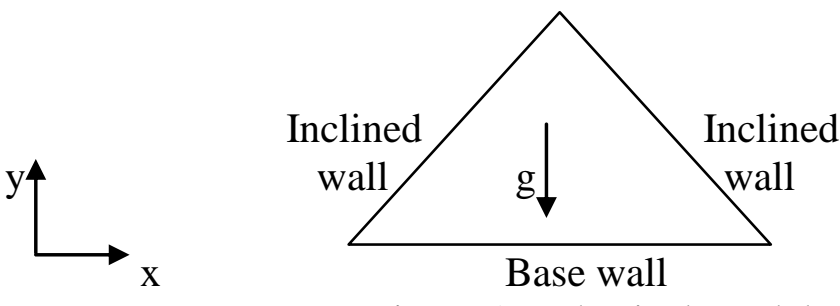

Figure 1: Physical Model

A long air-filled $(\operatorname{Pr}=0.71)$ triangular cavity with cross-section as shown in Fig. 1 is considered. The cavity extension in the direction perpendicular to the cross-section is more than double its width so that the flow and the heat transfer is taken to be two-dimensional [15]. The following sets of boundary conditions are used: summer conditions and winter conditions. The entire two-dimensional cavity is considered for both configurations. The idea of simulating the entire cavity rather than assume symmetry is borne out of the asymmetric results obtained by Karyakin et al. [13] for cavity heated from above and Holtzman et al. [10] for cavity heated from the base when the effects of symmetry assumption in triangular cavity results were studied.

The famous Reynolds Averaged Navier-Stokes (RANS) equations for turbulent natural convection, for incompressible flow, are 


$$
\begin{aligned}
\frac{\partial \bar{u}_{i}}{\partial x_{i}} & =0 \\
\frac{D \bar{u}_{i}}{D t} & =\beta \overline{\boldsymbol{T}}-T_{o} \bar{g}_{i}-\frac{1}{\rho} \frac{\partial \bar{p}}{\partial x_{i}}+v_{k} \frac{\partial^{2} \bar{u}_{i}}{\partial x_{j} \partial x_{j}}-\frac{\partial \overline{u_{i}^{\prime} u_{j}^{\prime}}}{\partial x_{i}} \\
\frac{D \bar{T}}{D t} & =\alpha \frac{\partial^{2} \bar{T}}{\partial x_{j} \partial x_{j}}-\frac{\partial \overline{u_{i}^{\prime} T^{\prime}}}{\partial x_{i}}
\end{aligned}
$$

Due to the two unknown turbulence terms $\overline{u_{i}^{\prime} u_{j}^{\prime}}$, the Reynolds stress, and $\overline{u_{i}^{\prime} T^{\prime}}$, turbulence heat flux, solution of the equations requires additional equations ensure closure of the equation system. This, thus, necessitate turbulence modelling. Baseline Reynolds Stress turbulence model as available in CFX CFD software package (version 5.7.1, 2005), and subject to Boussinesq approximations, was used. Buoyancy-driven flows in cavities with low levels of turbulence in the core region are characterized by inherent unsteadiness. This poses severe convergence problems for steady RANS simulations, in particular, when higher-order convection schemes and fine meshes are adopted [16]. As a result, it was found necessary to use unsteady RANS in the present study.

The finite volume solution method is used. The timestep selected is based on the timescale of the transient behaviour of the flow simulation. A simple timestep dependence study is used to determine the effect of the timestep size on the accuracy of the results. The maximum timestep size is estimated using the following relationship [16]:

$$
\Delta t_{\max } \approx 0.25 \sqrt{\frac{H}{\beta g \Delta T}} \approx 0.25 H / V_{0}
$$

To hasten convergence, for complex simulations as the Reynolds stress models, the converged results of a k- $\varepsilon$ model are used as the initial guess. Further details on the computational method are available in [21].

\section{Validation Procedure}

Validation of numerical predictions by comparing them with existing experimental results from cavities subjected to the same boundary conditions as the numerical cases is a necessity in CFD. It is a crucial part of our approach that we do not rest on a Computational Fluid Dynamics and heat transfer rationale alone, although that is the force of the present reported aspect of our work. Our overall approach consists of developing a computational method which will properly be able to predict heat transfer behaviour in square cavities, and then to use, as far as possible, the same method in triangular cavities since there are no experimental data available on the subject. The computational method employed was validated by simulating the experimental results of low turbulence natural convection experiment in a differentially heated $50--10^{\circ} \mathrm{C}$ square cavity with highly conducting horizontal walls $(\mathrm{h}=$ $2.24 \mathrm{~W} / \mathrm{m}^{2} \mathrm{~K}$ ) as performed by Tian and Karayiannis [17, 18] using the same Re Stress model.

Selecting the $\overline{u v} \operatorname{Re}$ stress distribution as an example, current prediction is compared with experimental results in Fig. 2. The results are in good agreement. The flow in the core of the cavity is quiescent. Turbulent flow is concentrated within the boundary layer and its intensity low. More results are presented in [19]. 


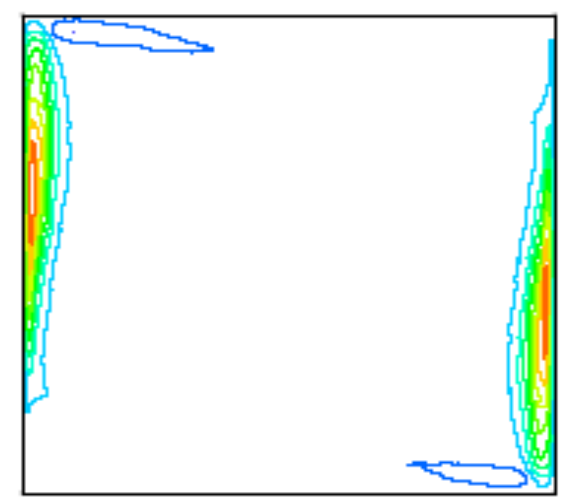

(a) Present study

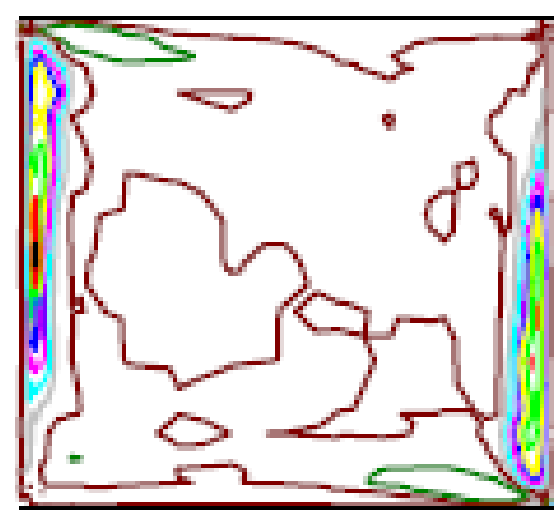

(b) Experiment

Figure 2: Comparison of $\overline{u v}$ Re stress distribution for the square cavity with the experiment of Tian and Karayiannis [18].

\section{Results and Discussion}

For the triangular cavity, four aspect ratios representing different pitch angles $18^{0}, 22^{1 / 2} 2^{0}, 45^{0}$, and $60^{\circ}$ were used for both summer and winter conditions. The results presented were tested for grid sizes, timesteps, averaging time and initial guessed flow field independence.

\subsection{Triangular cavity heated from the inclined walls: summer conditions}

For the isothermal boundary conditions, the surface temperature, $\mathrm{T}_{\mathrm{h}}$, of the hot inclined walls representing solar radiation absorbing aluminium roofing sheet on a very sunny, clear-sky day in a tropical climate was put at $70^{\circ} \mathrm{C}$. That of the horizontal base wall, $\mathrm{T}_{\mathrm{c}}$, representing the suspended ceiling above an air-conditioned space was taken to be $20^{\circ} \mathrm{C}$. For a typical traditional building, average width of the attic is 6 metres. This results in a Rayleigh number (Ra) range $10^{9} \leq \mathrm{Ra} \leq 10^{11}$ or $10^{10} \leq \mathrm{Gr} \leq 10^{12}$ for $0.33 \leq \mathrm{AR} \leq 1.73$. For isothermal boundary condition, the contour plots for AR 0.33 are presented in Fig. 3(a)-(e).

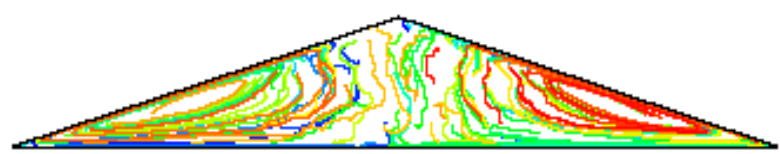

(a)

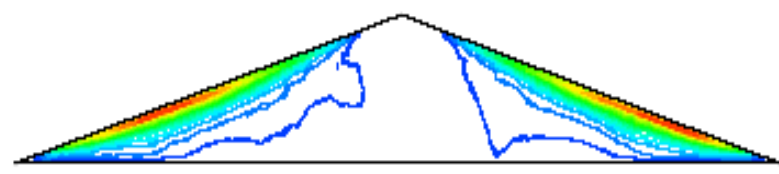

(c)

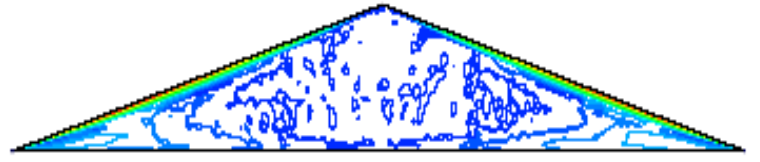

(b)

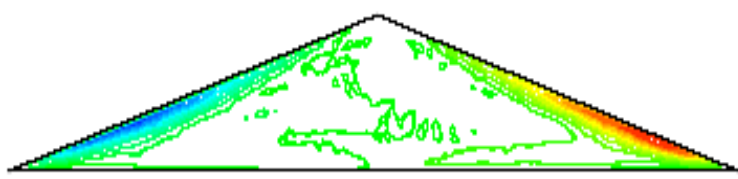

(d)

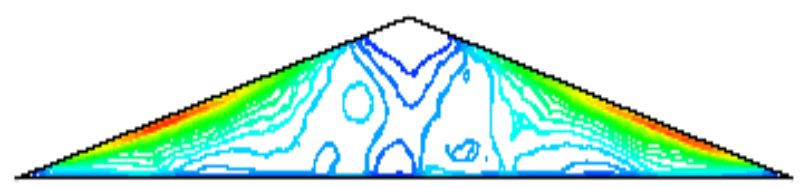

(e)

Figure 3: For the isothermal case, (a) Streamlines, (b) mean velocity distribution, (c) $\overline{u u}$ Reynolds stress distribution, (d) $\overline{u v}$ Reynolds stress distribution, (e) $\overline{v v}$ Reynolds stress distribution for AR $0.33\left(18^{0}\right.$-pitch cavity). 
The streamlines and the turbulent quantities presented show evidence of low turbulence in the flow within the cavity. However, the turbulence generated at the centres of the counterrotating cells as hot fluid rises along the inclined walls is damped as the flow descends the cavity at the midsection. Fig.3 (b) indicates that the flow is only stagnant at the apex region. The closeness of the hot and cold wall enhances heat transfer across the walls thereby promoting convective motion almost across the entire cavity. The Reynolds stresses reach maximum values at about one-third of the length of the inclined walls.

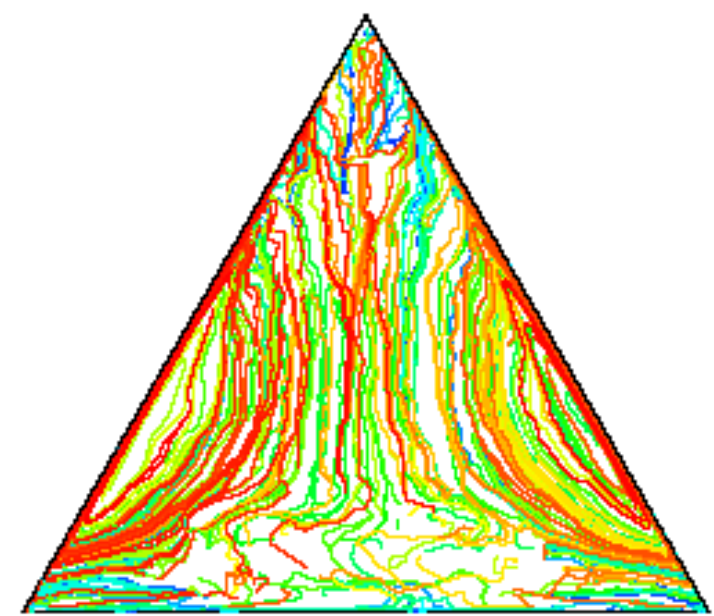

(a)

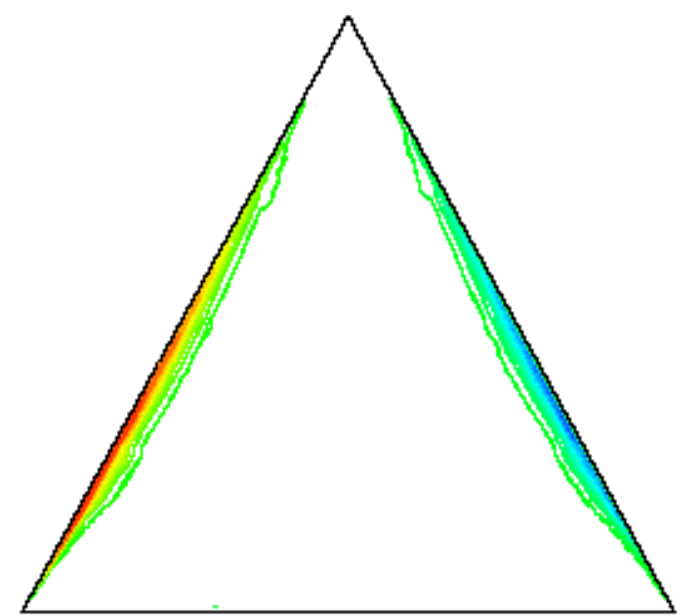

(b)

Figure 4: For the isoflux case, (a) streamlines, and (b) $\overline{u v}$ Reynolds stress distribution for the $60^{\circ}$-pitch cavity.

The streamlines and the $\overline{u v}$ Reynolds stress distribution for the $60^{\circ}$-pitch cavity are shown in Fig. 4. The stagnant fluid area at the middle of the base wall becomes larger. This is so because, as the pitch angle increases, the heat transfer to the cold base wall reduces. Therefore, heat exchange occurs mainly between the hot inclined walls and the fluid at the central part of the cavity. This reflects in the $\overline{u v}$ Reynolds stress distribution. Whereas the distribution covers almost the $18^{0}$-pitch cavity in Fig.3 (d), it is limited to near the hot inclined walls of the $60^{\circ}$-pitch cavity in Fig4 (b).

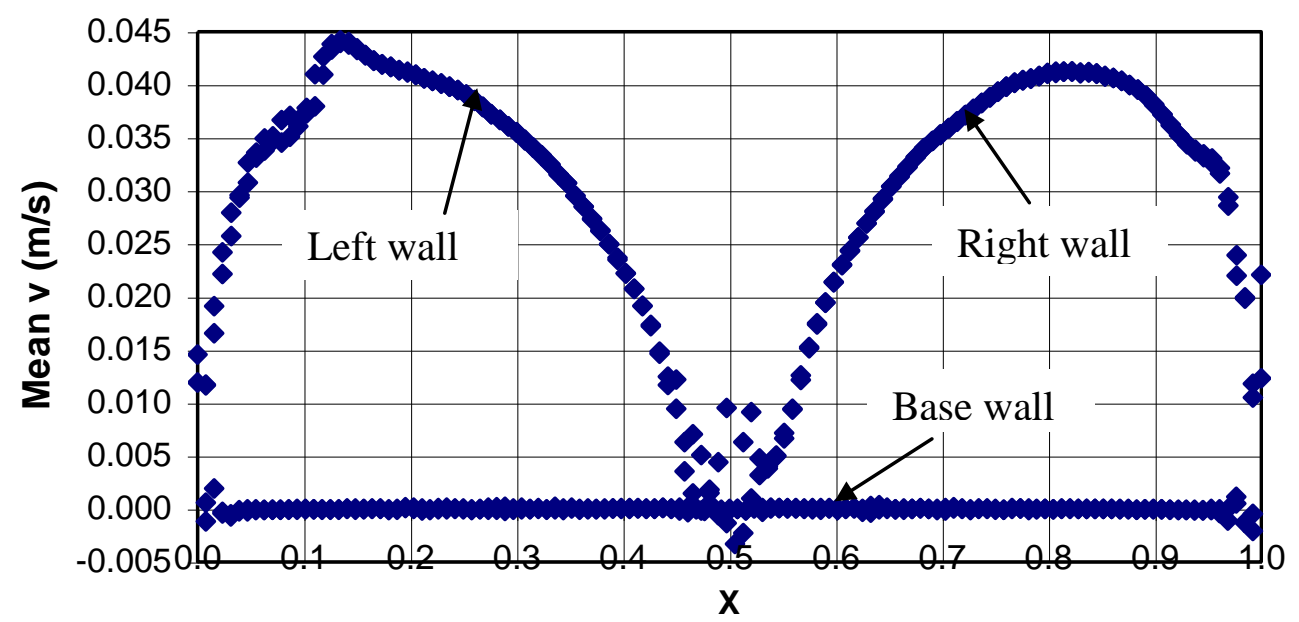

Figure 5: Mean vertical velocity across the field for the $18^{0}$-pitch cavity

The graphical plot of the mean vertical velocity across the $18^{0}$-pitch cavity when heated from the inclined walls isothermally, as presented in Fig. 5, shows rapid increase in flow velocity 
within the boundary layer along the left inclined wall to a peak value 0.044 at $X=0.13$. It reduces gradually as the flow approaches the apex region to a negative value at $X=0.5$ as the flow changes direction downward.

Similarly, the results for the isoflux boundary condition are presented in Fig. 6 (a)-(e).

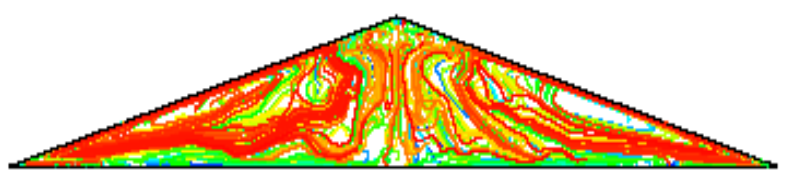

(a)

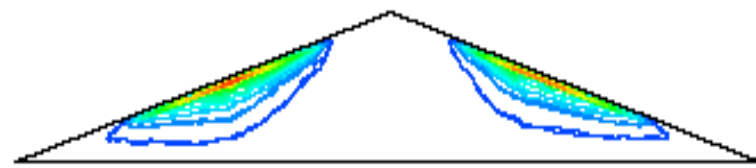

(c)

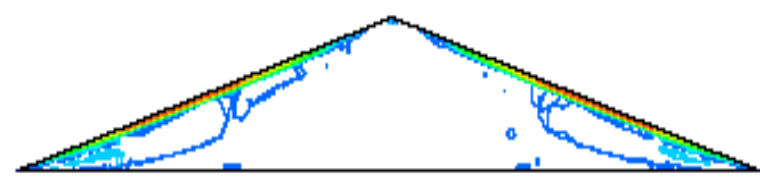

(b)

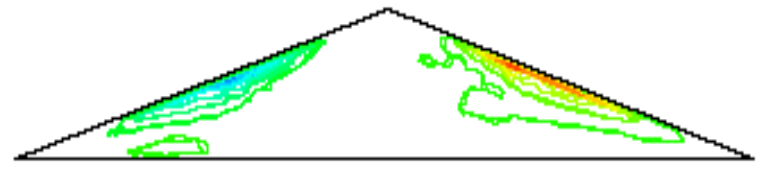

(d)

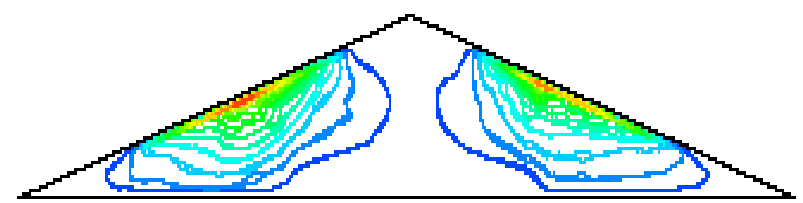

(e)

Figure 6: For the isoflux case, (a)Streamlines, (b) mean velocity distribution, (c) $\overline{u u}$ Reynolds stress distribution, (d) $\overline{u v}$ Reynolds stress distribution, (e) $\overline{v v}$ Reynolds stress distribution for AR 0.33 ( $18^{0}$-pitch cavity).

Convective fluid motion is initiated in the vicinity of the inclined walls because they are not perpendicular to the direction of gravity [20]. As in the isothermal case, the streamlines and the turbulent quantities presented also indicate evidence of low turbulence in the flow. It is observed in Fig.6 (b) that flow is restricted to a narrow region along the inclined walls i.e. limited to within the boundary layers and characterised by high velocity gradient. Whereas the Reynolds stresses reach maximum values at about one-third of the length of the inclined walls for the isothermal case, it attains peak value at about mid-height for the isoflux case.

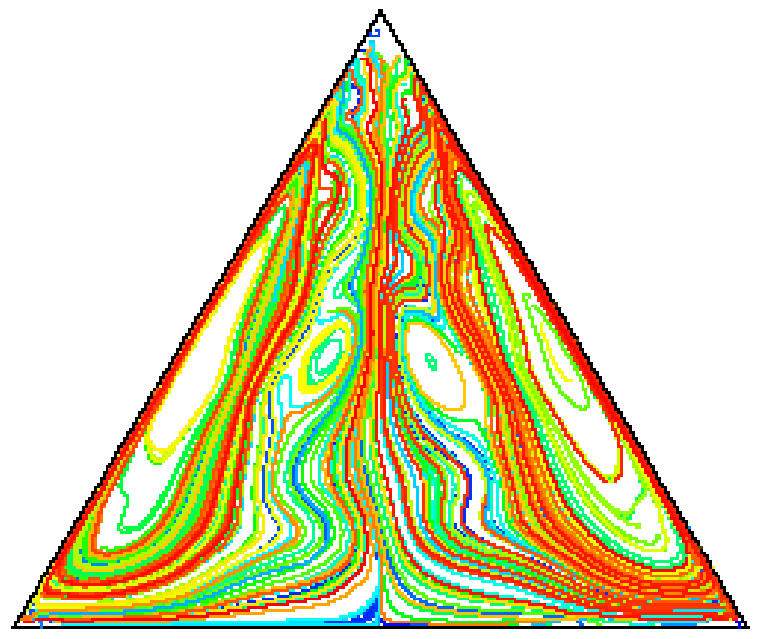

(a)

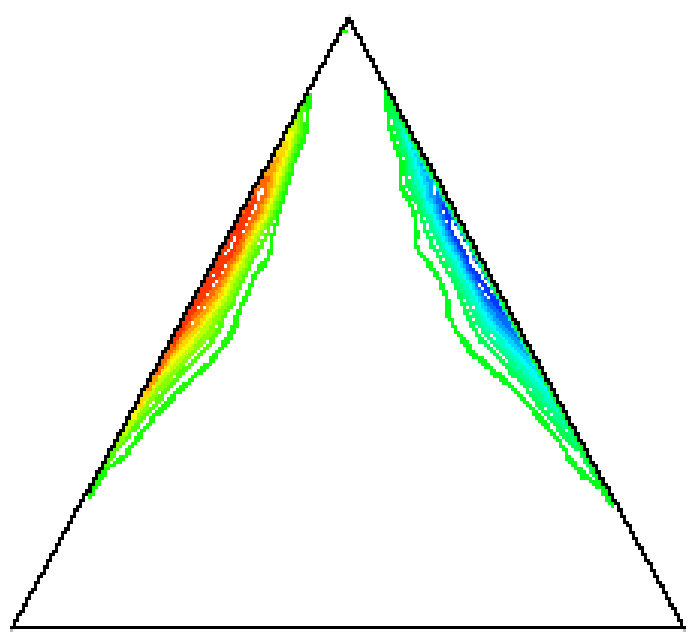

(b)

Figure 7: For the isoflux case, (a) streamlines, and (b) $\overline{u v}$ Reynolds stress distribution for the $60^{0}$-pitch cavity. 
The streamlines and the $\overline{u v}$ Reynolds stress distribution for the $60^{\circ}$-pitch cavity are shown in Fig. 7. Two large, high-velocity counter-rotating cells enclosing two, small low-velocity counter-rotating cells are observed. This agrees with the findings of Hasani and Chung [6] when they investigated similar boundary condition for laminar flow but with symmetry assumption. They observed that above a critical Rayleigh number, the single cell circulation formed bifurcates along the vertical side of the enclosure and a secondary cell rotating in the opposite direction to the primary vortex evolved.

\subsection{Triangular cavity heated from the base: winter conditions}

The base wall was assumed heated by the warm air within the space below the attic to the normal room temperature, $25^{\circ} \mathrm{C}$, as a result of the traditional hearth method of heating in the temperate regions while the inclined walls were assumed covered with snow at $0^{\circ} \mathrm{C}$. The Ra range is $10^{9} \leq \mathrm{Ra} \leq 10^{11}$ for $0.33 \leq \mathrm{AR} \leq 1.73$. The contour plots for AR 0.33 are presented in Fig. 8 (a)-(e).

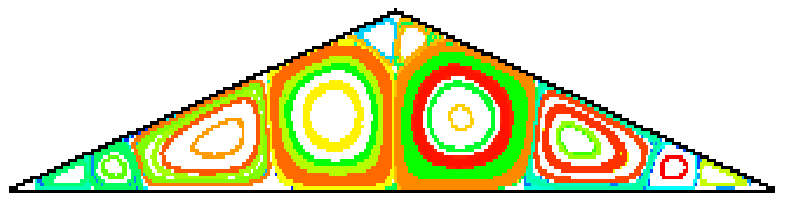

(a)

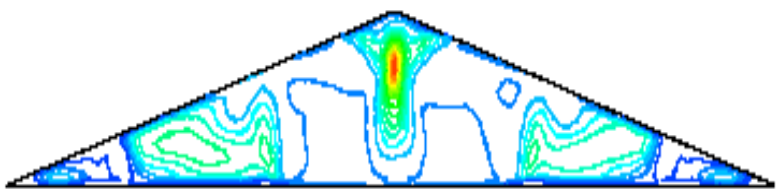

(c)

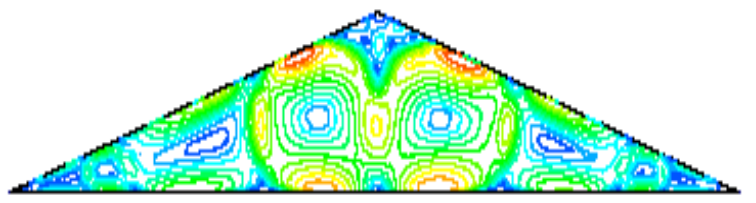

(b)

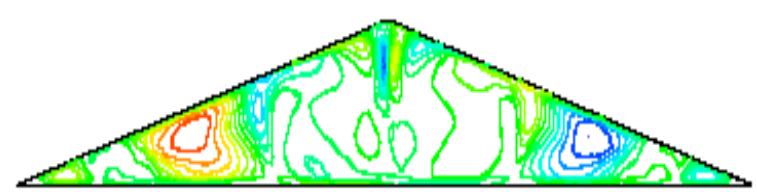

(d)

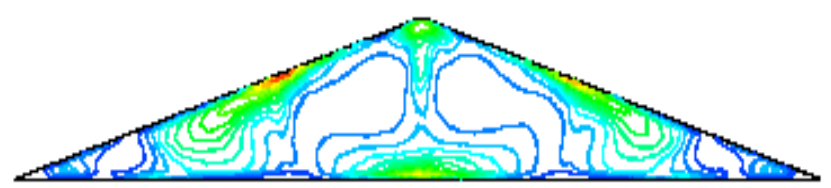

(e)

Figure 8: (a) Streamlines, (b) mean velocity distribution, (c) $\overline{u u}$ Reynolds stress distribution,

(d) $\overline{u v}$ Reynolds stress distribution, (e) $\overline{v v}$ Reynolds stress distribution for AR 0.33 $\left(18^{0}\right.$-pitch cavity).

An enclosure heated from below present a classical Rayleigh-Benard convection system. In a triangular cross-sectional enclosure, instabilities begin at the hot base and the vortex formed grows in size till the cold inclined wall is reached and then bifurcates into counter-rotating secondary cells. Fig. 8(a) shows ten fully developed counter-rotating cells. In Fig. 9(a), the number of cells for the $60^{\circ}$-pitch cavity has reduced to five. This is consistent with the conclusion reached by Bejan [1] that the number of cells increases with $\mathrm{Ra}$ and as the slope of the inclined walls decreases. 


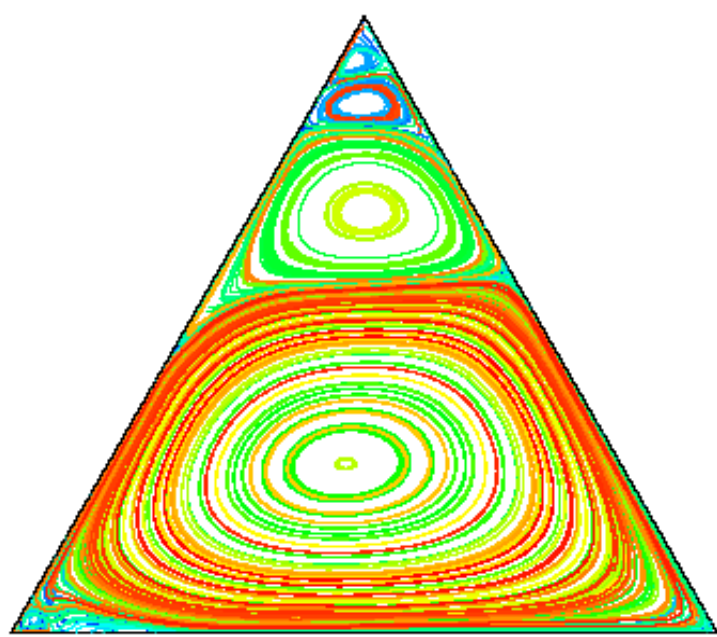

(a)

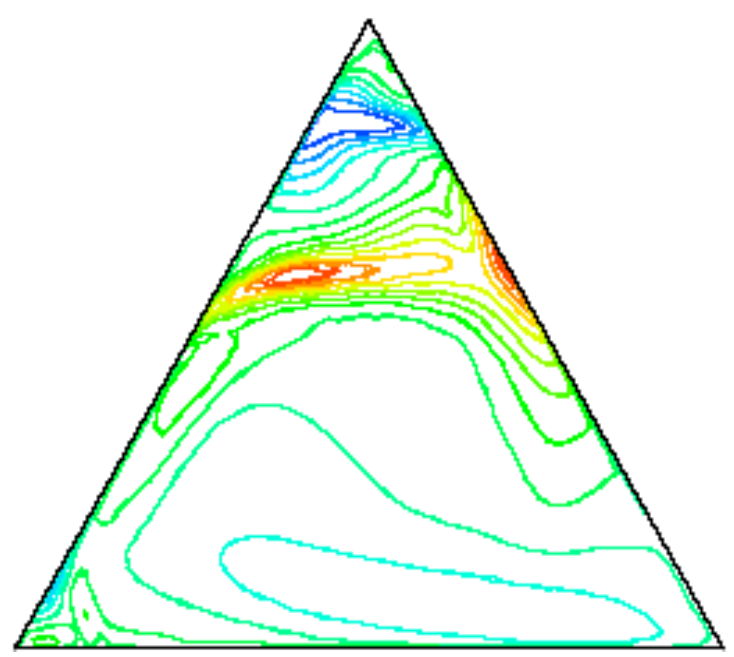

(b)

Figure 9: For the isoflux case, (a) streamlines, and (b) $\overline{u v}$ Reynolds stress distribution for the $60^{0}$-pitch cavity.

Examining the same problem, Hasani and Chung [6] also discovered, for laminar flow situation, that the number of cells increases with the Rayleigh number. However, while following the procedure reported by Hasani and Chung [6] to simulate an attic of about the size considered in the present study, Haese and Teubner [14] ended up with a flow dominated by single cell. This 'strange' result could be attributed to the symmetry assumption they made. Holtzman et al. [10] studied the effects of symmetry assumption and found that a pitchfork bifurcation occurs at a critical Grashof number above which the flow pattern becomes increasingly asymmetric and the number of counter-rotating cells increasing. The centralised arrangement of the cells in Fig.9 (a) underscores the adverse effects of symmetry assumption for this type of configuration.

The mean velocity contour plot, Fig.8 (b), shows that the two cells at the cavity centre rotate at much higher velocity than do others. This could be attributed to the large space existing there. The Reynolds stresses have high values around the area of contact of the counterrotating cells.

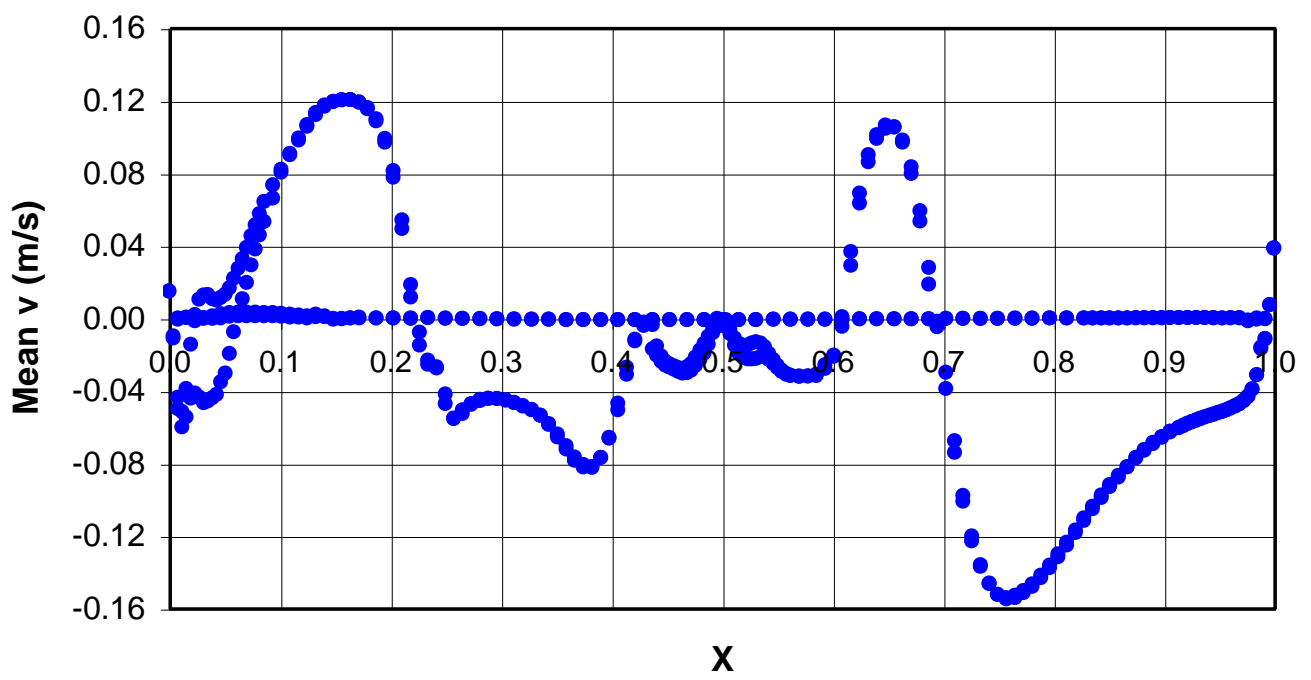

Figure 10: Mean vertical velocity across the field for the $60^{\circ}$-pitch cavity 
Figure 10 shows the graphical plot of the mean vertical velocity of the $60^{\circ}$-pitch cavity. The plot shows that the high velocity large cell at the lower part of the cavity rotates in clockwise direction with greater strength near the right inclined wall. The dwindling strength of the cells towards the midsection results in multiple peak values. Development of a small cell rotating in anticlockwise direction is observed near the left bottom corner.

\section{Heat Transfer and Performance Aspects}

The ultimate aim of our project is engineering one. It is to generate heat transfer and performance data, of quantitative reliability, leading to improved designs of roof space in the tropics. This will enable the designer, therefore, to minimise the cooling loads necessary to provide a given level of thermal comfort within the building and over the annual climatic cycle. Hence there are energy conservation and environmental consequences. However, in order to achieve the above, it is necessary fully to understand the fluid dynamics aspects, particularly when the situation is one of low turbulence rather than laminar flow. While this paper concentrates on fluids issues we have also paid equal attention to heat transfer and overall performance. This demands careful definitions of local Nusselt number and average heat transferred and these are fully reported in [21].

\section{Conclusions}

Time-dependent, two-dimensional turbulent natural convection of air contained in a long horizontal isosceles triangular enclosure has been investigated for both summer and winter conditions. The entire cavity was simulated. It is observed that the results are respectively generally symmetrical and asymmetrical for the two conditions. For the cavity heated through the inclined walls, results indicate a low level of turbulence that is restricted to the vicinity of the hot walls. The practical significance of the results is that the heat transported across the ceiling can be most effectively utilised when a heat extraction device is placed at the appropriate position. This would help both to reduce the size of the air-conditioning system required to cool the space below, and to eliminate the use of thermal insulation across the ceiling. By extending the period of thermal comfort within the space without reliance on mechanical air-conditioning, it thereby reduces the annual energy cost. This study and its defined parameter ranges have particular application to roof space design and thermal efficiency in the tropics. The work is also expected to be very useful to agriculturists engaging in rooftop drying of agricultural products.

\section{Nomenclature}

AR aspect ratio, $\mathrm{H} / \mathrm{L}$

g gravitational acceleration $\left(\mathrm{m} \mathrm{s}^{-2}\right)$

Gr Grashof number, $\frac{g \beta \Delta T H^{3}}{v^{2}}$

h heat transfer coefficient $\left(\mathrm{Wm}^{-2} \mathrm{~K}^{-1}\right)$

$\mathrm{H}$ cavity height $(\mathrm{m})$

L cavity half-width (m)

Pr Prandtl number, $v / \alpha$

Ra Rayleigh number, $\frac{g \beta \Delta T H^{3}}{\nu \alpha}$

$\mathrm{T} \quad$ temperature $(\mathrm{K})$ 
$\mathrm{u} \quad$ velocity in the $\mathrm{x}$-direction $\left(\mathrm{m} \mathrm{s}^{-1}\right)$

$\mathrm{v} \quad$ velocity in the $\mathrm{y}$-direction $\left(\mathrm{m} \mathrm{s}^{-1}\right)$

$\mathrm{x}, \mathrm{y}$ cartesian coordinate

\section{Greek symbols}

$\alpha \quad$ thermal diffusivity $\left(\mathrm{m}^{2} \mathrm{~s}^{-1}\right)$

$\beta \quad$ coefficient of thermal expansion $\left(\mathrm{K}^{-1}\right)$

$v \quad$ kinematic viscosity $\left(\mathrm{m}^{2} \mathrm{~s}^{-1}\right)$

$\Delta \quad$ difference

\section{superscript}

- $\quad$ mean value

subscripts

c cold-wall

h hot-wall

i index

\section{References}

[1] A. Bejan, Convective Heat Transfer, John Wiley \& Sons, New York, 2004.

[2] G.Z. Gershuni, E.M. Zhukhovitskiy, and D.L Shvartzblat, "Overcritical Convective Motions in Asymmetric Region", Hydrodynamics, 7: 89-95, 1974.

[3] T.J. Thirst, and S.D. Probert, "Heat Transfer Versus Pitch Angle for Nonventilated Triangular-Sectioned, Apex-Upward Air-Filled Spaces, In ASTM STP 660, R.P.Tye, ed., American Society for Testing and Materials, pp.203-210, 1978.

[4] V.A. Akinsete, and T.A. Coleman, "Heat Transfer by Steady Laminar Free Convection in Triangular Enclosures," Int. J. of Heat and Mass Transfer, 25: 991998, 1982.

[5] M. Ghassemi, and J.A. Roux, "Numerical Investigation of Natural Convection Within a Triangular Shaped Enclosure," In Heat Transfer in Convective Flows, R.K. Shah, ed., ASME, pp. 169-175, 1989.

[6] S.M.F. Hasani, and B.T.F. Chung, "Laminar Natural Convection in a Triangular Enclosure", In ASME,Ocean Engineering Division, D.T. Valentine, and C.C. Jahnke, eds., pp.107-116, 1997.

[7] H. Asan, and L. Namli, "Laminar Natural Convection in a Pitched Roof of Triangular Cross-Section: Summer Day Boundary Conditions”, J. Energy \& Buildings 33:69-73, 2000.

[8] D. Poulikakos, and A. Bejan, "The Fluid Dynamics of an Attic Space," Journal of Fluid Mechanics, 131:251-269, 1983.

[9] H. Salmun, "Convection Patterns in a Triangular Domain", Int. J. Heat and Mass Transfer 38: 351-362, 1995.

[10] G.A. Holtzman, R.W. Hill, and K.S. Ball, "Laminar Natural Convection in Isosceles Triangular Enclosures Heated from Below and Symmetrically Cooled from Above," J. Heat Transfer, 122:485-491, 2000.

[11] R. D. Flack, "The Experimental Measurement of Natural Convection Heat Transfer in Triangular Enclosures Heated or Cooled from Below," J. Heat Transfer, 102: 770772, 1980.

[12] E.M. del Campo, M. Sen, and E. Ramos, "Analysis of Laminar Natural Convection in Triangular Enclosure”, Numerical Heat Transfer, 13: 353-372, 1988. 
[13] Y.E. Karyakin, Y.A. Sokovishin, and O.G Martynenko, "Transient Natural Convection in Triangular Enclosures", Int. J. Heat and Mass Transfer 31:1759-1766, 1988.

[14] P.M. Haese, and M.D. Teubner, "Heat Exchange in an Attic Space," Int. J. of Heat and Mass Transfer, 45:4925-4936, 2002.

[15] F. Penot, and A. N'Dame, "Successive Bifurcations of Natural Convection in a Vertical Enclosure Heated from the Side," In Heat Transfer: Third UK National Conference and First European Conference on Thermal Sciences, Birmingham, UK, 1: 507-513, 1992.

[16] K.J. Hsieh, and F.S. Lien, "Numerical Modelling of Bouyancy-driven Turbulent Flows in Enclosures," Int. J. Heat and Fluid Flow, 25: 659-670, 2004.

[17] Y.S. Tian, and T.G. Karayiannis, 'Low Turbulence Natural Convection in Air Filled Square cavity, Part I: Thermal and Fluid Flow Fields,' Int. J. Heat and Mass Transfer, 43: 849-866, 2000.

[18] Y.S. Tian, and T.G. Karayiannis, 'Low Turbulence Natural Convection in Air Filled Square cavity, Part II: the Turbulence Quantities,' Int. J. Heat and Mass Transfer, 43:867-884, 2000.

[19] O.M. Kamiyo, M.W. Collins, and T.G. Karayiannis. Low Turbulence Natural Convection in Square and Triangular Enclosures. In Ninth UK National Heat Transfer Conference, University of Manchester, 2005.

[20] S.J. Robertson and L.W. Spradley, "Effect of Enclosure Shape on Natural Convection Velocities in Microgravity", Acta Astronautica, 13:727-733, 1986.

[21] O.M. Kamiyo. Low Turbulence Natural Convection in Triangular Enclosures: Numerical Results. Technical Report. Department of Mechanical Engineering, University of Lagos, Nigeria, 2006. 